\title{
RESONANT AUGER STUDIES OF METALLIC SYSTEMS
}

I. Coulthard ${ }^{1}$, W. J. Antel Jr., S. P. Frigo, and J. W. Freeland

Experimental Facilities Division, Argonne National Laboratory, 9700 South Cass $\mathrm{Av}$ Argonne, IL 60439, USA.

J. Moore, W. S. Calaway, M. J. Pellin, and M. Mendelsohn

Chemistry Division, Argonne National Laboratory, 9700 South Cass Avenue

Argonne, IL 60439, USA.

T. K. Sham, and S. J. Naftel

Chemistry Department, University of Western Ontario, London, Canada, N6A 5B7.

A. P. J. Stampfl ${ }^{2}$

Australian Synchrotron Research Program

Australian Nuclear Science and Technology Organization .

Lucas Heights, New South Wales, Australia.

\begin{abstract}
Results of resonant Auger spectroscopy experiments are presented for $\mathrm{Cu}, \mathrm{Co}$, and oxidized Al. Sub-lifetime narrowing of Auger spectra and generation of sub-lifetime narrowed absorption spectra constructed from Auger yield measurements, were observed.
\end{abstract}

'e-mail: coulthar@aps.anl.gov

2 currently at Experimental Facilities Division, Argonne National Laboratory
The submitted manuscript has been created by the University of Chicago as Operator of Argonne National Laboratory ("Argonne") under Contract No. W-31-109-ENG-38 with the U.S. Department of Energy. The U.S. Government retains for itself, and others acting on its behalf, a paid-up, nonexclusive, irrevocable worldwide license in said article to reproduce, prepare derivative works, distribute copies to the public, and perform publicly and display publicly, by or on behalf of the Government. 


\section{DISCLAIMER}

This report was prepared as an account of work sponsored by an agency of the United States Government. Neither the United States Government nor any agency thereof, nor any of their employees, make any warranty, express or implied, or assumes any legal liability or responsibility for the accuracy, completeness, or usefulness of any information, apparatus, product, or process disclosed, or represents that its use would not infringe privately owned rights. Reference herein to any specific commercial product, process, or service by trade name, trademark, manufacturer, or otherwise does not necessarily constitute or imply its endorsement, recommendation, or favoring by the United States Government or any agency thereof. The views and opinions of authors expressed herein do not necessarily state or reflect those of the United States Government or any agency thereof. 


\section{DISCLAIMER}

Portions of this document may be illegible in electronic image products. Images are produced from the best available original document. 
Resonant Auger yields are used to identify three valence states of oxidized Al. Partial absorption yield spectra were derived giving detailed electronic information and thickness information for the various chemical states of the bulk metal, the passivating aluminum oxide layer, and the metal-oxide interface region. In addition, the total absorption yield spectrum for the oxidized Al sample was constructed from the partial yield data, supporting the consistency of our method.

\section{INTRODUCTION}

Excitation energies far away from resonant conditions have been traditionally used to generate Auger electrons, where the Auger effect can be approximated by a two-step model which consists of the generation of a vacancy and its subsequent decay. Vacancy lifetimes play a key role in the inherent width of the spectral features observed when measurements are made far above absorption. Near an absorption edge however, the process of excitation and decay are coupled leading to a double photoionization event that may be described in terms of an inelastic scattering model. ${ }^{1}$ A wealth of interesting features near resonance results. So called spectator lines ${ }^{2}$ of constant binding energy, due to excitation into bound states, may be observed at the absorption edge and are due to the same effect sometimes observed in radiationless resonant Raman scattering (RRRS) ${ }^{24}$ Furthermore, as the Auger line width is no longer limited by the intrinsic lifetime, sublifetime spectral widths may be observed given a sufficiently narrow excitation bandwidth. ${ }^{1}$ Since Auger emission across a resonance reflects the density of unoccupied states that was probed by the selected transition, ${ }^{5}$ absorption spectra may be measured using the Auger yield detection. Combined with sub-lifetime effects, the potential arises to determine the chemical and electronic nature of mixed valence systems. Work on resonant 
Auger spectroscopy has focused upon sub-lifetime narrowing issues, ${ }^{6-8}$ spectator lines, ${ }^{9-11}$ and other studies of the Auger process itself. ${ }^{12-14}$

Here, we report the results of soft $\mathrm{x}$-ray experiments using the resonant Auger effect. In addition to demonstrating traditional resonant Auger measurements. The ability to use resonant Auger signal as a probe to measure partial absorption yields from samples of mixed valence is demonstrated in this paper.

\section{EXPERIMENTAL}

The experiments were performed on the SRI-CAT 2-ID-C soft x-ray beam-line at the Advanced Photon Source. ${ }^{15}$ The beam-line consists of a spherical grating monochromator (SGM) with a series of gratings to provide an operational energy range of 0.5 to $3.0 \mathrm{keV}$ and resolving powers up to 10000 . The beam size on the sample is approximately $0.5 \mathrm{~mm}$ in height by $2.0 \mathrm{~mm}$ in width. A flux of $10^{12}$ photons / second reaches the sample at a resolving power of approximately 5000. The UHV experimental chamber is equipped with a Physical Electronics 10-366HR hemispherical energy analyzer with 16-channeltron detection and up to $\sim 25 \mathrm{meV}$ resolution. The analyzer was mounted at $53^{\circ}$ with respect to the incident photons in the horizontal plane. Auger yield measurements were recorded using the peak height as the photon energy was scanned across the resonance. Incident photon flux was monitored using a high-transmission gold mesh. Normal absorption measurements were recorded in total electron yield (TEY) mode by monitoring the charge compensation current and in total fluorescence yield (TFY) mode using a silicon photodiode. The $\mathrm{Al}, \mathrm{Cu}, \mathrm{Co}$ samples were foils of minimum $99.99 \%$ purity acquired from Johnson Mathey. The $\mathrm{Cu}$ and $\mathrm{Co}$ were sputter cleaned prior to analysis using $1 \mathrm{keV}$ and an Ar pressure of $5 \times 10^{-5}$ Torr. The Al sample examined was left in an ambient oxidized condition. 


\section{RESULTS AND DISCUSSION}

Resonant sub-lifetime narrowing effects are clearly visible in the Cu LMM Auger spectra shown in Fig. 1. One spectrum was acquired at the $\mathrm{Cu} \mathrm{L}_{3}$-edge, the other at a photon energy $675 \mathrm{eV}$ above the edge. All other conditions with respect to the beam line and hemispherical analyzer resolution were kept the same. A significant decrease is observed in the width of the Auger peak off resonance, $1.62 \mathrm{eV}$, to on resonance, $0.94 \mathrm{eV}$. Narrowing is also observed in absorption spectra using Auger emission as a probe of the transition. Figure 2 shows the absorption spectra from clean Co. The Auger yield measurement was narrower than the TEY spectrum. Spectral features that are unresolveable due to the lifetime effects in off resonance may be resolveable in the resonance regime.

For many materials, the kinetic energy of Auger electrons are sensitive to their valence state. Auger shifts are often larger than photoemission core level shifts on the same sample ${ }^{16-19}$. The Si $2 p$ core level for example, is shifted by $\sim 4.2 \mathrm{eV}$ between $\mathrm{Si}$ and $\mathrm{SiO}_{2}$, while the Si KLL Auger is shifted by $\sim 8.1 \mathrm{eV} .{ }^{16}$ Using specific Auger emission as a probe, partial absorption yield spectra for mixed valence states can be collected. Figure 3 shows the TEY and TFY spectra for oxidized Al. Sampling depths for each mode are different due to the different escape depths of electrons $(50 \AA)$ versus X-rays ( $1000 \AA)$. The ratio of the features at 1546 and $1552 \mathrm{eV}$ between the two spectra are different since the sampling depth of each experimental mode is different. A greater fraction of the total TFY signal comes from the bulk non-oxidized metal compared to the more surface sensitive TEY signal. This system may be used to show the ability of resonant Auger spectroscopy to differentiate between different valencies and extract partial absorption yields for each state.

Figure 4 shows Auger spectra for oxidized Al at four incident photon energies spanning the $\mathrm{Al} \mathrm{K}$-edge. Three distinct Auger peaks are clearly observed, and each 
modulates in intensity differently across the edge. We believe that the different modulations indicate the presence of different valence states within the oxidized Al. There are three different chemical states of the Al: Al bulk metal, $\mathrm{E}_{\mathrm{k}}=1388 \mathrm{eV},{ }^{20}$ surface oxide $\mathrm{Al}_{2} \mathrm{O}_{3}, \mathrm{E}_{\mathrm{k}}=1382 \mathrm{eV},{ }^{20}$ and an interface region in between the oxide and the metal in which the oxidation is only partially complete, $\mathrm{E}_{\mathrm{k}}=1385 \mathrm{eV} \cdot{ }^{21-23}$ Using an Auger spectrum (not shown) well above the edge, these three peaks were fitted using Lorenztians allowing thicknesses of 25,2 , and $4 \AA$ for the surface oxide, metal-oxide interface, and bulk metal respectively to be estimated. ${ }^{24}$ The escape depth of the Auger electrons in this experiment are such that only a small portion of the non-oxidized bulk of the sample can be observed. The interface between metal and oxide has been observed previously, ${ }^{21-23}$ however, measurements were performed on extremely thin oxide layers (1-2 monolayers) grown under carefully controlled conditions using highly surface sensitive photoelectrons of a few tens of $\mathrm{eV}$ in kinetic energy and absorption measurements at the $\mathrm{Al} 2 \mathrm{p}$ level. Resonant Auger measurements using KLL emission of $\sim 1385 \mathrm{eV}$ provides a way of probing interfaces buried under thick oxide layers due to the comparatively large escape depths of the electrons at these energies.

Figure 5 shows the results of collecting partial absorption yields, for each of these three valence states, across the Al K-edge. Each spectrum is a result of the different valence states probed. The contribution of the metal/oxide interface to the absorption spectrum of the sample is small but measurable using Auger emission. Its presence is not measurable from the TEY and TFY, shown in Fig. 3. The TEY/TFY signal from the interface layer is buried under the signals from the two other valence states. The interface region contributes at most only a few percent to the total yield spectrum as surface sensitive TEY samples a depth of $\sim 50 \AA,{ }^{25}$.

Ideally the sum of these partial yield spectra should reproduce the total yield measured from the sample. Figure 6 compares the TEY spectrum and the sum of the partial yields extracted from the resonant Auger spectra. The partial yield of the non-oxidized $\mathrm{Al}$ 
layer were scaled prior to addition to reflect the different depth sensitivities of TEY and Auger measurements. ${ }^{24}$ In the Auger spectra, the bulk Al metal contributed only $\sim 10 \%$ to the entire signal, whereas in TEY the metal contributes $\sim 50 \%$ to the signal based upon the escape depths of the detected electrons for each technique. ${ }^{24}$ Both spectra agree quite well both in terms of intensity and in the shape of the near-edge features.

\section{CONCLUSIONS}

Resonant Auger experiments on a variety of metallic systems were studied. Partial absorption yields were measured for oxidized $\mathrm{Al}$ and three valence states were resolved showing that resonant Auger emission may be used to resolve chemical and electronic features in mixed valence materials.

Work at Argonne is supported by the U.S. Department of Energy, Basic Energy Sciences, under contract No. W-31-109-Eng-38.

Work at the University of Western Ontario was supported by a grant from the National Sciences and Engineering Research Council of Canada 


\section{REFERENCES}

1 G.S. Brown, M.H. Chen, B. Crasemann, and G.E. Ice, Phys. Rev. Lett. 45, 1937 (1980).

2 C.J. Sparks, Phys. Rev. Lett. 33, 262 (1974).

3 P. Eisenberger, P.M. Platzman, and H. Winick, Phys. Rev. Lett. 36, 623 (1976).

4 Y.B. Bannett, and I. Freund, Phys. Rev. Lett. 34, 372(1975).

5 W. Drube, R. Treusch, and G. Materlik, Phys. Rev. Lett. 74, 42 (1995).

6 A. Kivimäki, A. Naves de Brito, S. Aksela, O.-P. Sairanen, A. Ausmees, S.J.

Osborne, L.B. Dantas, and S. Svensson, Phys. Rev. Lett. 71, 4307 (1993).

7 Z.F. Liu, G.M. Bancroft, K.H. Tan, and M. Schachter, Phys. Rev. Lett.72, 621 (1994).

8 W. Drube, Radiat. Phys. Chem. 51, 335 (1998).

9 G.B. Armen, T. Åberg, J.c. Levin, B. Crasemann, M.H. Chen, G.E. Ice, and G.S. Brown. Phys. Rev. Lett. 54, 1142 (1985).

10 A. Kivimäki, H. Aksela, and O.-P. Sairanen. Phys. Rev. B. 47, 4181 (1993).

11 Y. Baba, T.A. Sasaki, H. Yamamoto, Phys. Rev. B. 49, 709 (1994).

12 W. Drube, R. Treusch, and G. Materlik, Phys. Rev. Lett. 74, 42 (1995).

13 T.M. Grehk, W. Drube, G. Materlik, J.E. Hansen, and T.K. Sham, J. Elec. Spect. and Relat. Phenom. 88-91, 241 (1998).

14 T.M. Grehk, W. Drube, R. Treusch, and G. Materlik, Phys. Rev. B. 57, 6422 (1998).

15 K.J. Randall, E. Gluskin, and Z. Xu, Rev. Sci. Instrum. 66, 4081 (1995).

16 C.D. Wagner, D.E. Passoja, H.F. Hillery, T.G. Kinisky, H.A. Six, W.T. Jansen, and J.A. Taylor, J. Vac. Sci. Technol. 21, 933 (1982).

17 M.K. Bahl, R.O. Woodall, R.L. Watson, and K.J. Irgolic, J. Chem.Phys. 64, 1210 (1976). 
18 S.W. Gaarenstroom, and N.J. Winograd, J. Chem. Phys. 67, 3500 (1977).

19 C.D. Wagner, and J.A. Taylor, J. Electron Spectrosc. Relat. Phenom. 28, 211 (1982).

20 J.A. Taylor, J. Vac. Sci. Technol. 20, 751 (1982).

21 S.A. Flodström, R.Z. Bachrach, R.S. Bauer, and S.B.M. Hagström, Phys. Rev. Lett. 37, 1282 (1976).

22 A. Bianconi, R.Z. Bachrach, S.B.M. Hagström, and S.A. Flodström, Phys. Rev. B. 19, 2837 (1979).

23 G. Faraci, S. La Rosa, A.R. Pennisi, Y. Hwu, and G. Margaritondo, J. Appl. Phys. 78, 4091 (1995).

24 Unpublished results.

25 Estimated from the universal electron escape depth curve assuming that the primary source of TEY signal is from secondary electrons of a few $\mathrm{eV}$ in kinetic energy.

\section{FIGURE CAPTIONS}

Figure 1. Comparison of $\mathrm{Cu} \mathrm{L}_{3} \mathrm{M}_{4,5} \mathrm{M}_{4,5}$ Auger spectra taken on, $+0 \mathrm{eV}$, and off $+675 \mathrm{eV}$, resonance with respect to the $\mathrm{Cu} \mathrm{L}_{3}$-edge.

Figure 2. Comparison of $\mathrm{Co} \mathrm{L}_{3}$-edges measured by TEY and resonant Auger yield methods.

Figure 3. Al K-edge for oxidized Al collected in TEY and TFY modes. 
Figure 4. Comparison of Al KLL Auger spectra taken at various excitation energies across the Al K-edge for oxidized Al.

Figure 5. Partial Auger yields for three valence states of oxidised Al.

Figure 6. Comparison of TEY to the sum of partial yields generated from resonant Auger spectra for oxidized Al. 


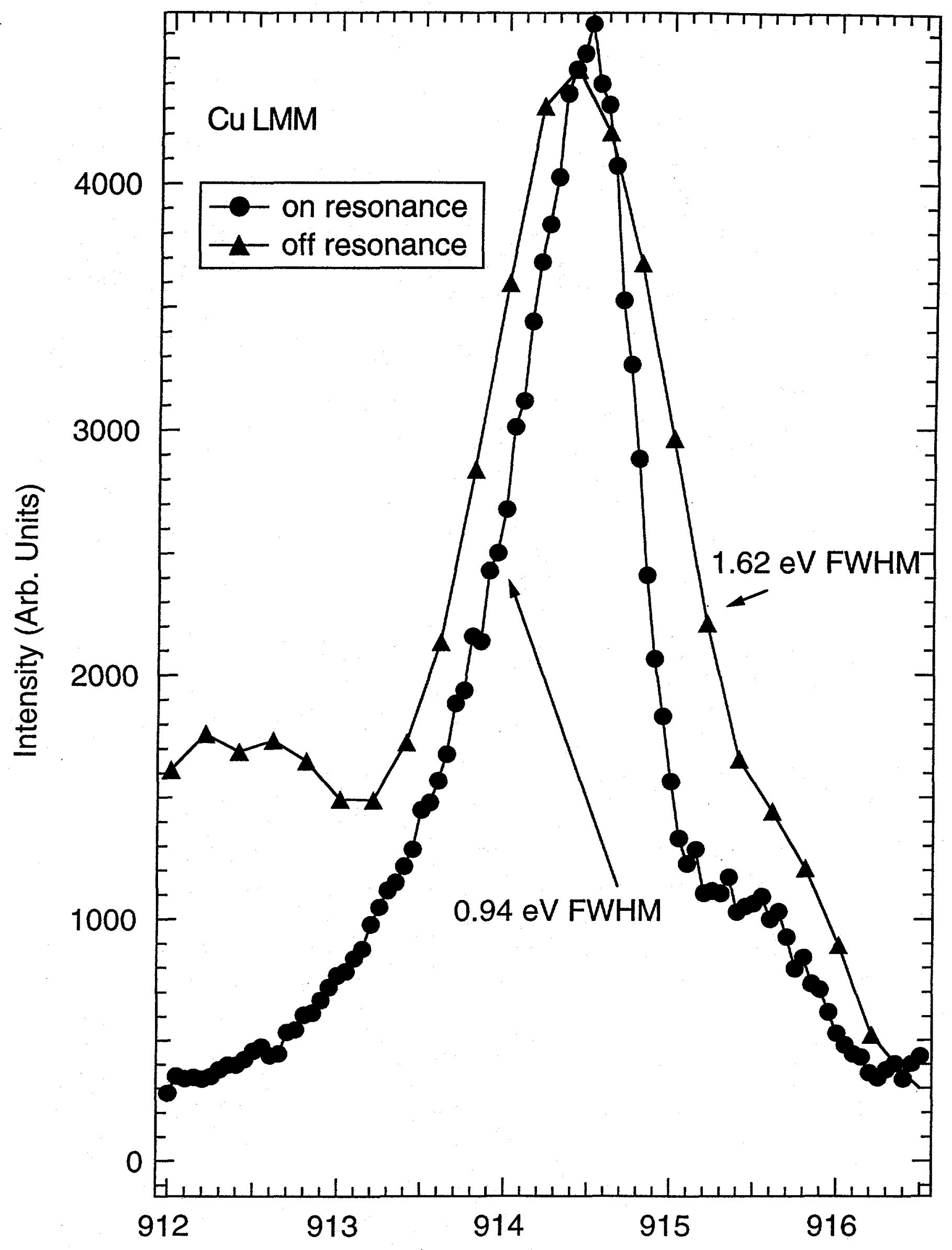

Kinetic Energy (eV) 


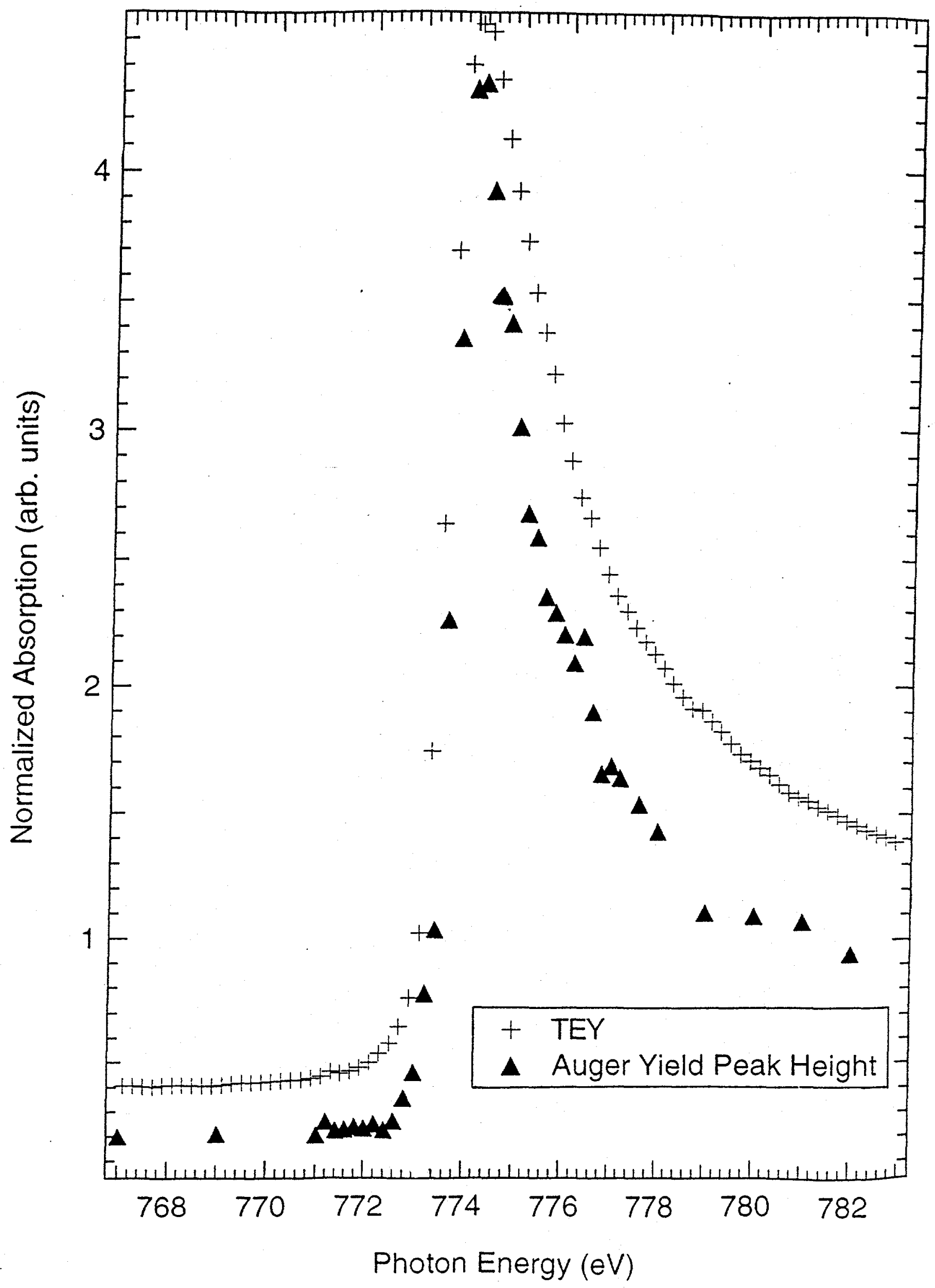

$F$ 


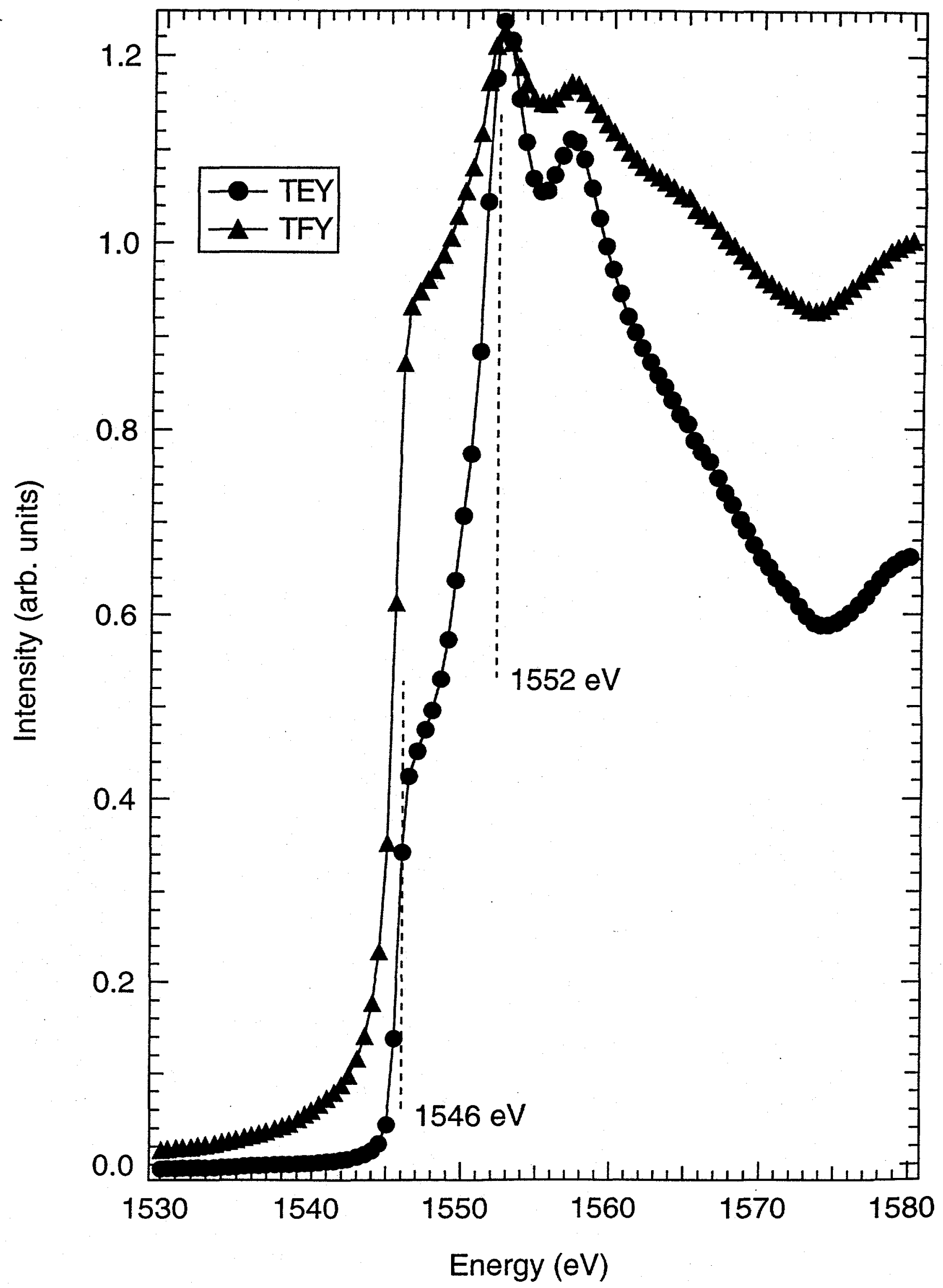

Fig. 3 

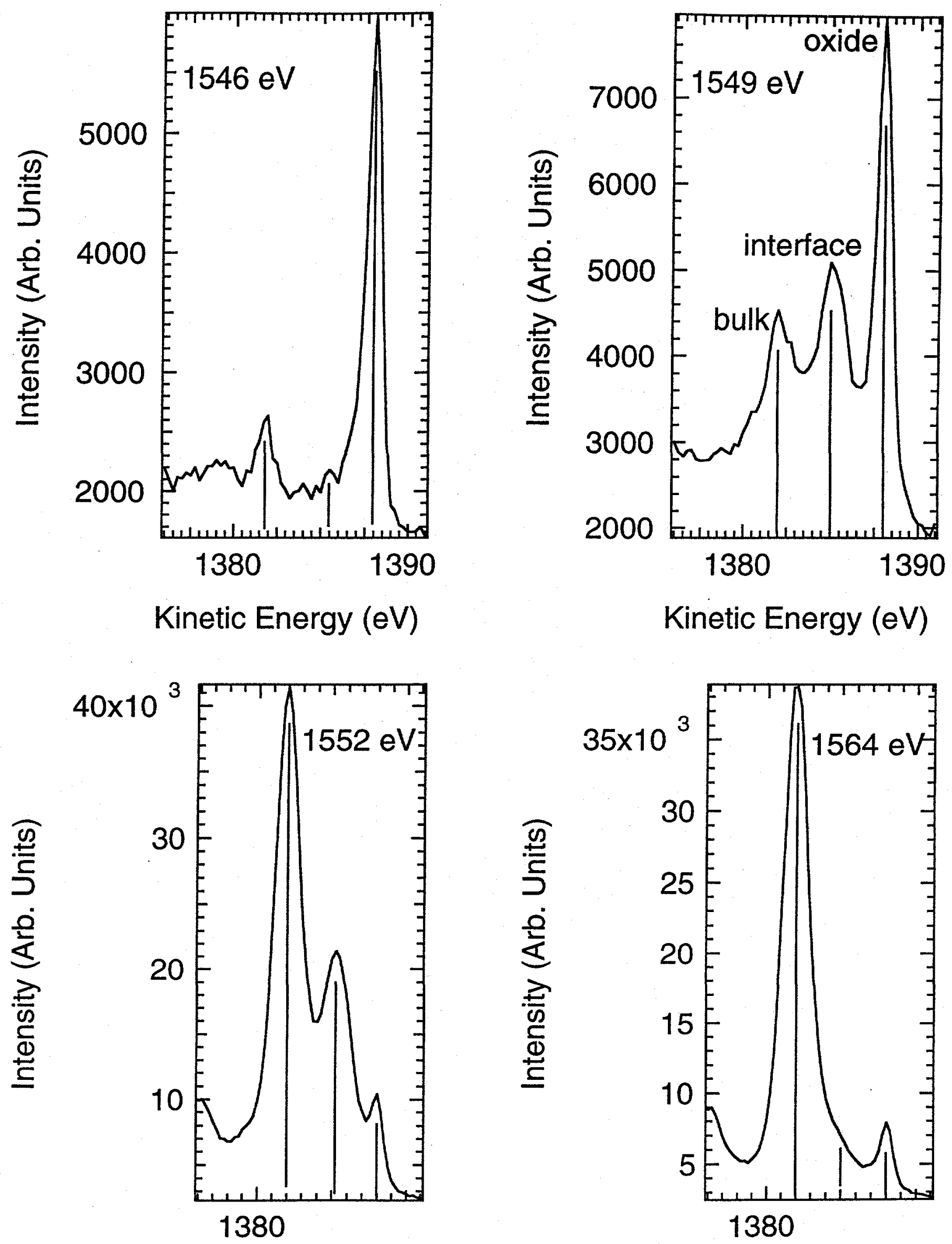

Kinetic Energy (eV)

Kinetic Energy (eV) 


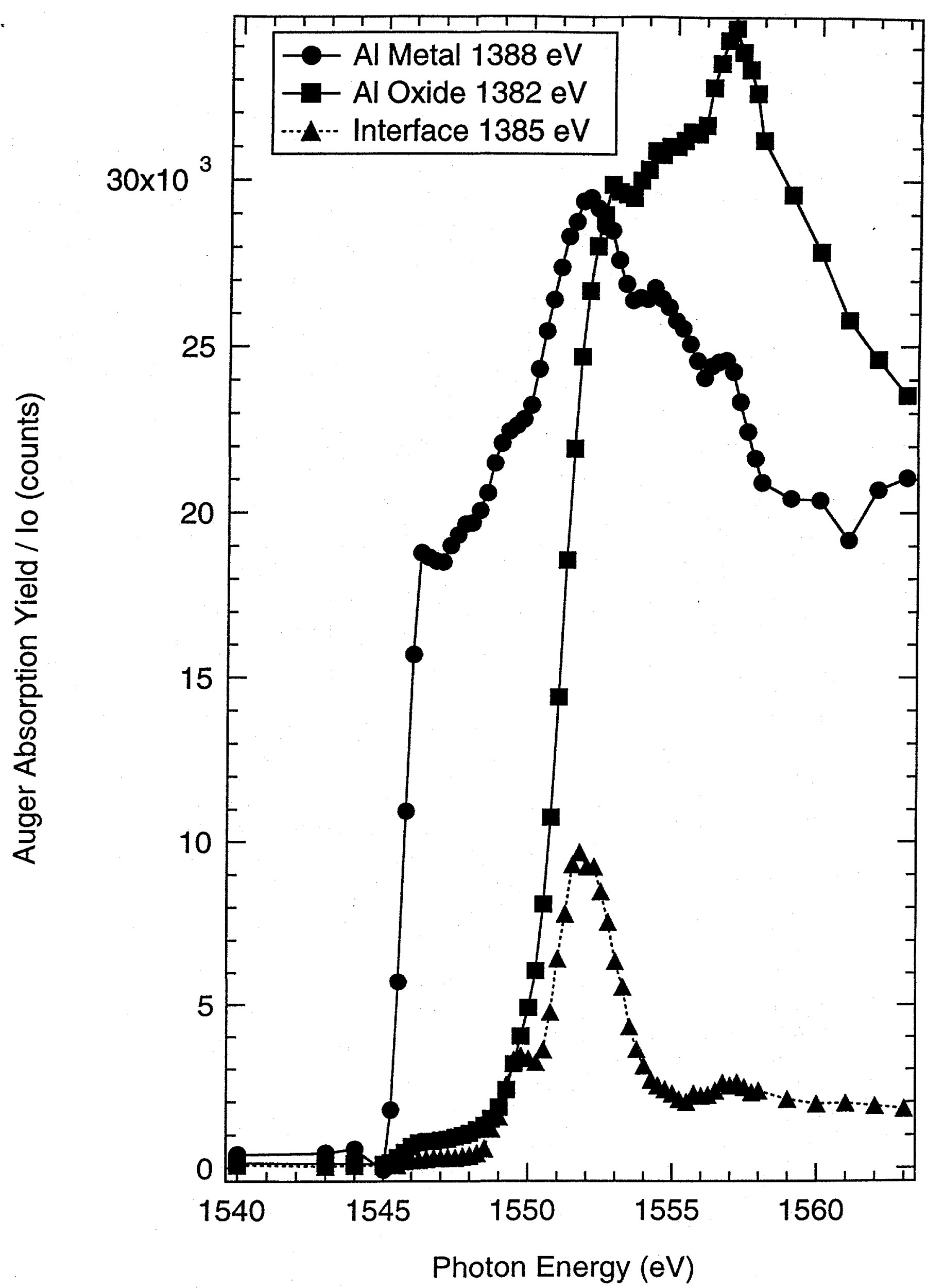

$F_{0 .} .5$ 


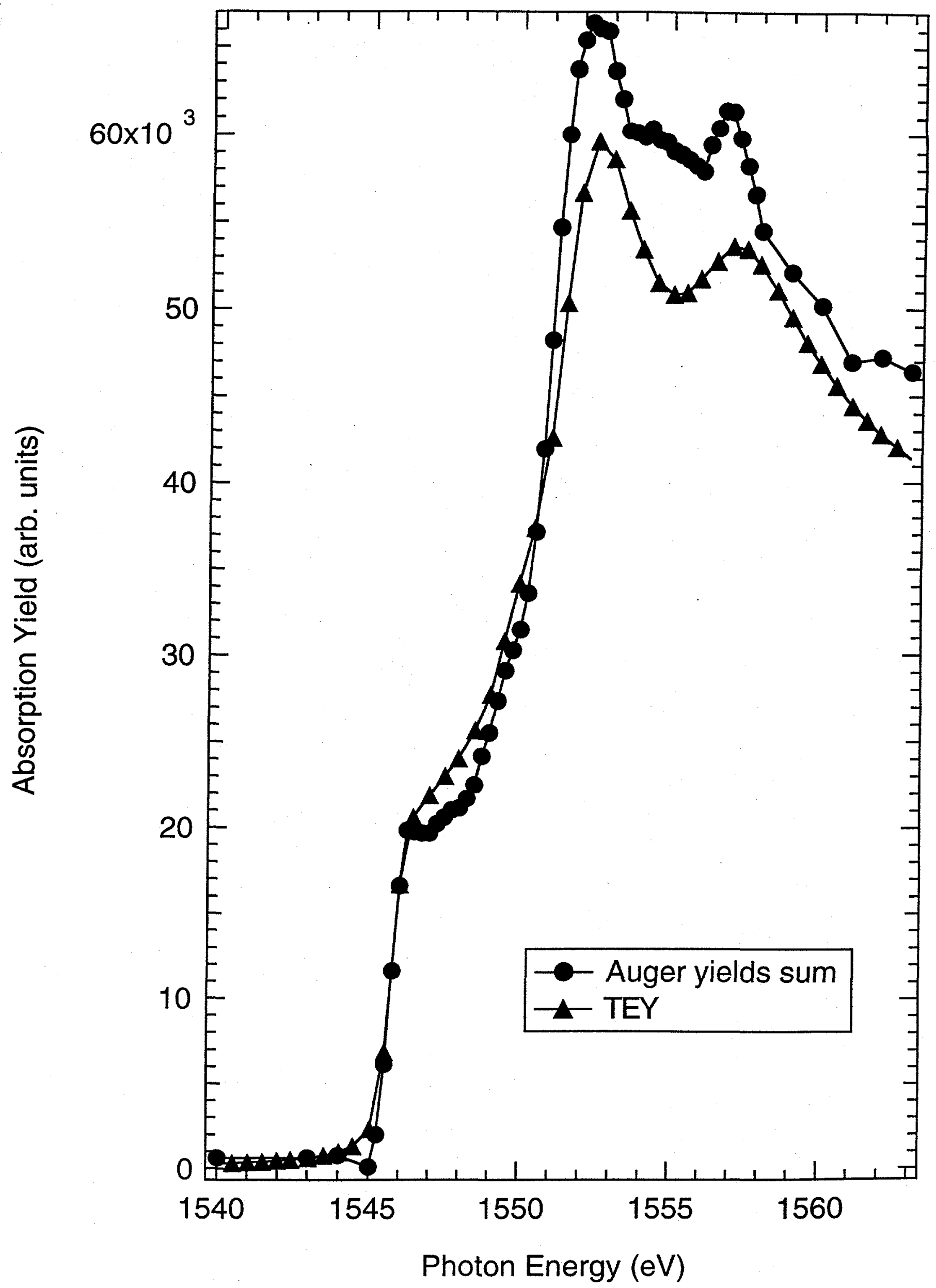

$F_{\text {gg. }} .6$ 